\title{
Exosomal miRNAs as potential biomarkers of cardiovascular risk in children
}

Abdelnaby Khalyfa, ${ }^{1,2^{*}}$ and David Gozal ${ }^{1}$

\begin{abstract}
Intercellular interactions are essential for basic cellular activities and errors in either receiving or transferring these signals have shown to cause pathological conditions. These signals are not only regulated by membrane surface molecules but also by soluble secreted proteins, thereby allowing for an exquisite coordination of cell functions. Exosomes are released by cells upon fusion of multivesicular bodies (MVB) with the plasma membrane. Their envelope reflects their cellular origin and their surface and internal contents include important signaling components. Exosomes contain a wide variety of proteins, lipids, RNAs, non-transcribed RNAs, miRNAs and small RNAs that are representative to their cellular origin and shuttle from donor cells to recipient cells. The exosome formation cargo content and delivery is of immense biological interest because exosomes are believed to play major roles in various pathological conditions, and therefore provide unique opportunities for biomarker discovery and development of non-invasive diagnostics when examined in biological fluids such as urine and blood plasma. For example, circulating miRNAs in exosomes have been applied as functional biomarkers for diagnosis and outcomes prediction, while synthetic miRNAs in polymer-based nanoparticles are applicable for therapeutics. This review provides insights into the composition and functional properties of exosomes, and focuses on their potential value as diagnostic markers in the context of cardiovascular disease risk estimates in children who suffer from conditions associated with heightened prevalence of adverse cardiovascular disease, namely obesity and sleep-disordered-breathing.
\end{abstract}

\section{Cardiovascular disease risk in children: obesity and obstructive sleep apnea as prototypic risk factors} Cardiovascular diseases (CVDs) are the major source of global morbidity and death and more people die annually from CVDs that from any other disease. With the increased worldwide prevalence of obesity, widely regarded as an independent risk factor for a range of chronic diseases including type 2 diabetes and cardiovascular disease [1], a heightened morbidity and mortality from many cardiovascular conditions including hypertension, dyslipidemia, and coronary artery disease has emerged $[2,3]$.

In children, obesity is associated with increased risk for multifaceted derangements in metabolic and cardiovascular function, including endothelial dysfunction (ED) [4-6]. In general terms, overweight children are more likely to prematurely develop ED, hypertension and type 2 diabetes,

\footnotetext{
* Correspondence: akhalyfa@uchicago.edu
${ }^{1}$ Section of Pediatric Sleep Medicine, Department of Pediatrics, Comer

* Correspondence: akhalyfa@uchicago.edu
'Section of Pediatric Sleep Medicine, Department of Pediatrics, Comer Children's Hospital, Pritzker School of Medicine, The University of Chicago, Chicago, IL, USA

${ }^{2}$ Department of Pediatrics, University of Chicago, 900 E, 57th Street, KCBD,

4112, Chicago, IL 60637, USA
}

an array of conditions that would normally be only found in older obese adults [7]. Recently, we have reported that obesity in children is associated with an increased risk for the development of ED, even prior to the onset of hypertension [5]. A recent statement by the American Heart Association has clearly identified the marked increases in long-term cardiovascular risk associated with childhood obesity [8]. Indeed, even short periods of overweight or obesity during childhood have been linked to earlier mortality in adulthood [9]. Therefore, early detection of children at risk for such adverse outcomes would be critically important to enable a more personalized intervention aiming at CVD risk reduction. Although measurement of 24-hour systemic blood pressure, assessment of intimamedia thickness and of endothelial function have all been advocated as potentially providing approaches for CVD risk stratification, their implementation in the clinical setting is fraught with objective difficulties that preclude their universal implementation $[10,11]$. Thus, delineation of more readily detectable biomarkers would definitely be desirable. To this effect, assays of hsCRP have unfortunately failed to deliver with sufficiently predictive precision, 
thereby reinforcing the need for development of more accurate predictive approaches of CVD risk in pediatric populations [12-14].

\section{Characteristics of biomarkers}

To enable the use of exosomal contents to serve as useful and implementable clinical biomarkers, several conditions need to be met. Indeed, a biomarker must be accurate, sensitive and specific; it needs to be altered in the relevant disease, and be able to discriminate between healthy and diseased subjects; quantification of the biomarker should be reliable and reproducible; the biomarkers should be consistent in different circumstances at different times, and the results from biomarker assays should be easy to interpret. A biomarker for diagnostic purposes should ideally be obtained from readily accessible body fluids, such as blood plasma, urine, and saliva and provide the clinicians with diagnostic information and aid in the medical decision making process [15-17].

Several circulating miRNAs in plasma have been successfully identified as biomarkers for a number of diseases including oncological and non-oncological conditions [18-20], and undoubtedly have come to play increasingly important roles in clinical applications such as disease diagnostics, monitoring therapeutic effects and predicting recurrence in specific patient populations. Specifically, circulating miRNAs have many characteristics of good biomarkers. (1) miRNAs are stable in the circulation and resistant to storage handling, and serum miRNAs are resistant to RNase digestion and other harsh conditions such as extreme $\mathrm{pH}$, boiling, extended storage, and multiple freeze-thaw cycles.

(2) Most miRNAs sequences are conserved across species.

(3) Changes in miRNA levels in circulation have been associated with different diseases as well as with certain biological or pathological stages. (4) miRNAs levels can easily be determined by various methods [21-24]. Thus far, there are few if any studies on the study of miRNAs in children as biomarkers indicative of potential risk of cardiovascular disease, and such void represents a unique opportunity for the field $[25,26]$.

\section{Cellular communication}

It is now firmly established that communications between cells are essential for appropriate development and function. The classical modes of intercellular communication involve cell junctions, adhesion contacts, and soluble factors that can act upon the same cell where they are produced, or upon neighboring cells, or may even act over long distances in an endocrine manner [27]. Cells can communicate directly with each other through cell-cell contact or at a distance using secreted soluble mediators. In multicellular organisms, cells can communicate via extracellular molecules such as nucleotides, lipids, or proteins. In addition, cells release various types of membrane vesicles into the extracellular space that differ in origin, size, morphology and content to best adapt to their surrounding microenvironment. These extracellular vesicles contain numerous proteins, lipids, and even nucleic acids (Couzin, 2005), and are released in the extracellular space and bind to receptors on other cells, thus modifying intracellular signaling in the recipient cells. Cells may release membrane vesicles into their extracellular environment either by pocketing them off directly from the plasma membrane or through secretion by endocytic compartments [28]. These small, defined vesicles released by cells have been variously termed"exosomes","microparticles","microvesicles", and"apoptotic blebs", and their nomenclature is strictly based on size, density, and membrane composition (for more details see http://www.microvesicles.org/).

Extracellular vesicles contain defined patterns of mRNA, miRNA, long non-coding RNA, and occasionally genomic DNA, and therefore their contributions to cellular trafficking consists in the transfer of genetic information that in turn induces transient or persistent phenotypic changes in the recipient cells $[29,30]$. Most circulating small RNAs (sRNAs) are contained within lipids or lipoprotein complexes, apoptotic bodies or exosomes that efficiently protect them from degradation by serum ribonucleases. Several reports have now demonstrated that RNAs contained within exosomes can be transferred and modulate the function of the recipient cells [29,31,32].

The important roles of extracellular vesicles in the pathogenesis of various diseases have recently been the object of substantial attention and research. These efforts have been particularly focused on cellular communication in the context of how organized sets of molecules may be involved in many different cellular processes, have the capacity to transmit antigenic information and can be easily recovered from fluids. Another emerging area of discovery that is not related to exosomes, and yet involves mechanisms by which cells relay information to other cells, has been the identification of long, thin, interconnecting membranous bridges that connect neighboring cells through adhesion mechanisms or tunneling nanotubes that can establish direct tubular conduits between the cytoplasms of adjacent cells [33]. Thus, both extracellular and intercellular connectivities are emerging and providing a unique opportunity to explore normal homeostatic processes, disease states, and therapeutics. Here we will review our current understanding on exosomes, and how the latter can serve in the context of cardiovascular disease risk identification and prevention in children.

\section{Exosome biogenesis and compositions}

Exosomes are one of several cell-secreted vesicles, which include microvesicles, ectosomes, membrane particles, exosome-like vesicle's and apoptotic bodies. Exosomes exhibit pleiotropic biological functions, including immune 
response, antigen presentation, intracellular communication and the transfer of RNA and proteins. The features and characteristics of the 3 major cell-derived microvesicle types are listed in Table 1.

Exosomes are 30-100-nm diameter membrane vesicles of endocytic origin that are released by most cell types upon fusion of multivesicular bodies (MVB) with the plasma membrane, presumably as a vehicle for cellfree intercellular communication. Exosomes were first described during the 1980s as organelles aimed at removing cell debris and unwanted molecules. For example, during reticulocyte maturation the transferrin receptor and many membrane-associated proteins were shed in small membrane vesicles via an unknown secretory process $[37,38]$, essentially with exosomes functioning as cellular garbage disposals. Since then, exosomes have emerged as important mediators of cellular communication that are involved in both normal physiological processes, such as lactation [38], immune response [39], and development and progression of diseases, such as liver disease [40], neurodegenerative diseases [41], and cardiovascular disease [42]. While the complete array of biological functions played by exosomes remains unclear, they clearly mediate communications between cells and facilitate processes such as antigen presentation as well as trans-signaling to neighboring cells [43].

Exosomes are secreted by many cell types, including B cells [44], T cells [45], dendritic cells [46], mast cells [47], platelets [48], and tumor cells [49]. In addition, exosomes have been found in bodily fluids, including urine and amniotic fluid [50], serum [51], plasma [52], saliva [39], breast milk [39,53], cerebrospinal fluid [54], and nasal secretions [55], suggesting that these microvesicles may be exploited as biomarkers in the diagnosis of disease [56,57].
Biochemical and proteomic analysis of exosomes further uncovered that these vesicles contain, besides a common set of membrane and cytosolic molecules, cell-type specific proteins that characterize their functional activity [58]. The mechanisms involved in protein sorting and loading into the exosome are still under investigation, but clearly involve ubiquitin and Endosomal Sorting Complex Required for Transport (ESCRT) machinery in this process. Exosomes are generated as intraluminal vesicles (ILVs) by a mechanism of"reverse budding" of the limiting membrane of late endosomes, which become multivesicular bodies (MVBs) when their lumen contains ILVs. When MVBs fuse with the plasma membrane, their cargo of ILVs is released to the extracellular space, as illustrated in Figure 1. A number of molecules are involved in the biogenesis and secretion of exosomes such as the ESCRT complex which is responsible for the sorting of proteins/cargos in the of MVBs [59]. Recently, a ceramide-dependent mechanism via neutral sphingomyelinase 2 (nSMase2) was proposed to be implicated in the regulation of exosome secretion [60]. Other molecules regulating the docking and fusion of MVBs with the plasma membrane are Rab proteins and SNARE (Soluble NSF Attachment Protein Receptor) proteins [59].

Exosomes can interact with recipient target cells via different mechanisms such as fusion with the plasma membrane or adhesion to corresponding receptors on the plasma membrane [61]. Several lines of evidence suggest that induction of intracellular calcium [61], overexpression of Rab11 or citron kinase [62] as well as a reduction in membrane cholesterol, or inhibition of cholesterol biosynthesis [63], could stimulate the release of exosomes into the microenvironment.

Extracellular membrane vesicles, play important pleiotropic roles in many biological processes, and are enriched in various bioactive molecules, such as growth factors,

Table 1 Key features of the main extracellular vesicle populations

\begin{tabular}{|c|c|c|c|}
\hline Feature & Exosomes & Microvesicles & Apoptotic bodies \\
\hline 1-Size & $40-100 \mathrm{~nm}$ & $100-1000 \mathrm{~nm}$ & $1000-5000$ \\
\hline 2-Markers & CD63, CD9, Alix, and TSG101 & $\begin{array}{l}\text { Annexin } V \text {, integrin, } \\
\text { selectin, flotillim-2 }\end{array}$ & Annexin, DNA, histones \\
\hline 3-Cell shapes & $\begin{array}{l}\text { Multivesicular bodies fusion } \\
\text { with plasmatic membrane }\end{array}$ & Membrane blebbing & Cell shrinkage and cell death \\
\hline 4-Contents & Proteins, RNA, and miRNA & $\begin{array}{l}\text { Proteins, RNA, and miRNA } \\
\text { Membrane permeable }\end{array}$ & $\begin{array}{l}\text { Cell organelles, proteins, DNA, } \\
\text { RNA, and miRNA }\end{array}$ \\
\hline 5-Detection methods & $\begin{array}{l}\text { FACS with CD68 capture, electron microscopy, } \\
\text { Western blot for exosomes enriched markers }\end{array}$ & FACS and electron microscopy & FACS and electron microscopy \\
\hline 6- Isolation method & $\begin{array}{l}\text { Ultracentrifugation (100,000-200,000 g), } \\
\text { precipitation, ultracentrifugation with } \\
\text { density gradient Immunoprecipitation } \\
\text { (ExoQuick) }\end{array}$ & Ultracentrifugation $(10,000-60,000 \mathrm{~g})$ & No standardized method \\
\hline 7-Mechanism of release & Exocytosis of MVBs & Budding from plasma membrane & $\begin{array}{l}\text { Cell shrinkage and plasma membrane } \\
\text { blebbing during cell death }\end{array}$ \\
\hline References & [34] & [35] & {$[36]$} \\
\hline
\end{tabular}




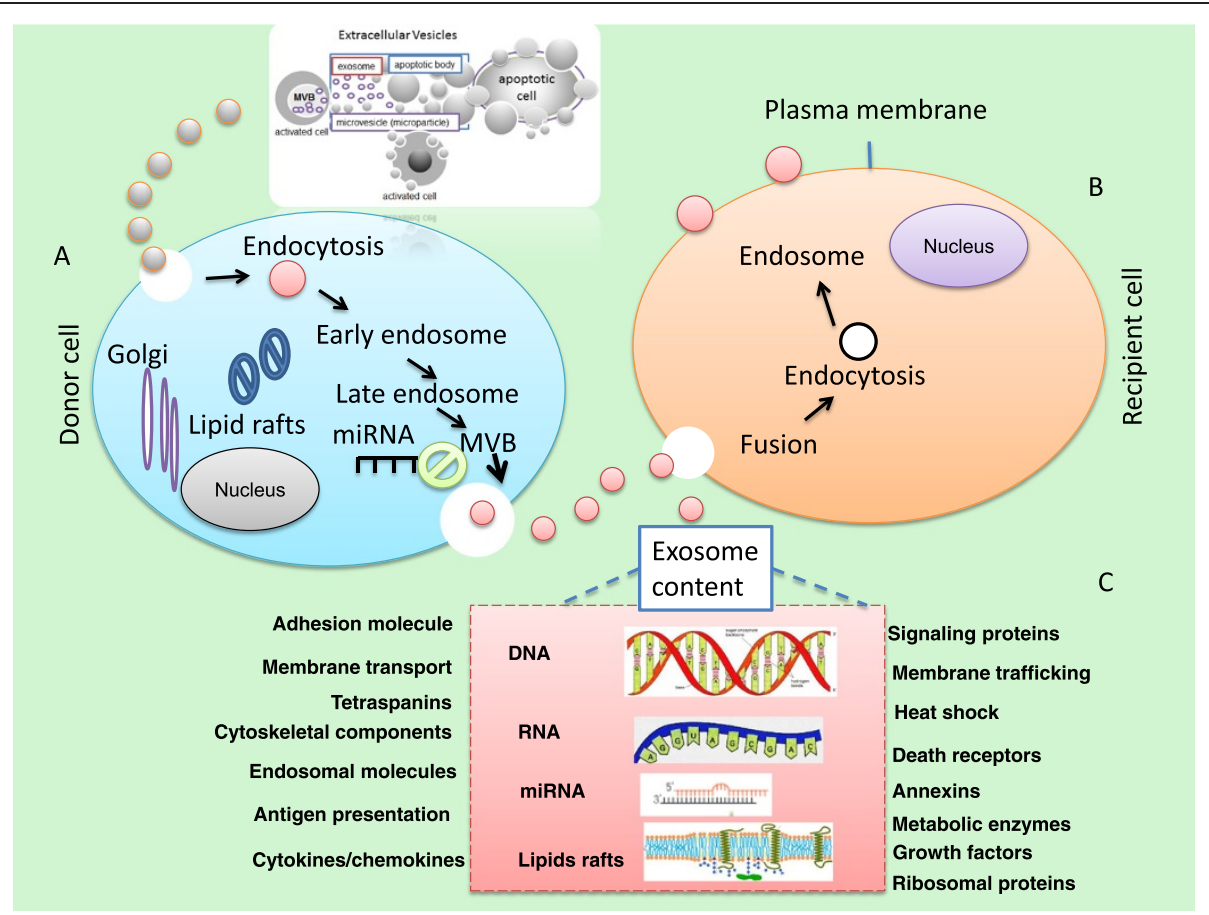

Figure 1 Schematic representation of extracellular vesicles (EVs) and the transfer of genetic material by exosomes. These EVs include different types of membrane vesicles (apoptotic bodies [ABs], microparticles/microvesicles, and exosomes), which can be found in body fluids including plasma and urine. The signals of extracellular vesicles can be activated through different steps based on environmental stimuli such as stress or hypoxia. Extracellular signals activate the fusion of multivesicular bodies (MVBs) into the plasma membrane and foster the release of their intraluminal vesicles (ILVs) as exosomes from the donor cells as illustrated in Panel (A). Once the exosomes are released and reach their targets they will start to fuse with the recipient cells (Panel B). Some proteins are directed by the ESCRT (endosomal sorting complex required for transport) machinery to the MVB route. Extracellular vesicles, which are secreted into the extracellular environment, contain functional molecules that can be taken up by recipient cells through mechanisms that include fusion with the plasma membrane, phagocytosis and endocytosis. Panel (C) represents the content of exosomes which contains a large array of proteins some of which are involved in membrane transport and fusion (such as RAB proteins and annexins), cytoskeletal proteins, adhesion molecules and tetraspanins, lipid rafts, as well as RNA (mainly miRNA and RNA), and DNA. Exosome membranes are enriched in lipid-based rafts such as cholesterol, ceramide and sphingolipids.

lipids, membrane receptors, mRNA, miRNA, transcriptional factors. Of note, circulating miRNAs, for example, are released from the parental cells to the extracellular milieu in highly stable forms, and in order to be protected from degradation by extracellular RNases, these cellular miRNAs can be released as soluble ribonucleoprotein complexes or inside cell-derived vesicles. In blood, the majority of cell-free miRNA is associated with the protein Argonaute 2 (AGO2), a main component of the RNA-induced silencing complex (RISC). These AGO2-miRNA complexes protect circulating soluble miRNAs from degradation by RNases present in plasma.

The bioactive molecules contained in exosomes have been suggested to (1) directly stimulate target cells via bioactive lipids or by acting like soluble cell-surface signaling complexes; (2) transfer oncogenic cargo and cancer cell properties to proximate indolent or normal cells; and (3) epigenetically reprogram recipient cells via the transfer of mRNA, miRNAmicroRNA, and transcription factors.
Exosomes can be transported between different cells and influence physiological pathways in the recipient cells. Exosome composition varies depending on the cell type of origin. Recent information from different cell type reveals that exosomes may contains a large variety of constitutive elements. Indeed, 4,563 proteins, 194 lipids, 1639 mRNA and 764 miRNA were identified in exosomes [34,64] demonstrating their complexity and potential functional diversity (see below).

\section{Exosome protein composition}

The protein composition of exosomes isolated from different cell sources has now been analyzed by different techniques including proteomics, Western blots and flow cytometry (FACS). These proteins essentially reflect both the cell type from which they are secreted and their endosomal origin, as well as their possible physiological roles and targeting properties $[65,66]$. Proteomic analysis of exosomes generated from different cell types/lines and 
biological fluids revealed that exosomes have common characteristic marker proteins on their surface or in their lumen, which are proteins from the cytosol, the plasma membrane, but also from the Golgi apparatus and endoplasmic reticulum $[58,66,67]$ (see Figure 1). As illustrated in Figure 1, the intercellular communication signals can be stimulated based on environmental stimuli. The message (s) transmitted by these intercellular communications may include growth, division, survival, differentiation, stress responses, and apoptosis signaling. The apoptotic bodies can be released as blebs of apoptotic cells, and they are characterized by phosphatidylserine externalization and contain fragmented DNA. Interestingly, exosomes can carry complex biological information consisting of mRNAs, miRNAs, as well as soluble and transmembrane proteins between cells.

One important challenge in the study of exosomes has been the lack of robust, reproducible isolation methods to obtain highly pure and well-characterized vesicular populations. Several strategies have been used for exosome isolation based on their size. There are 4 different methods that have been proposed to isolate and characterize exosomes including: (1) ultra-centrifugation [68], (2) ultrafiltration [69], (3) immunoprecipitation technologies with the use of antibody-loaded magnetic cell beads [70], and more recently (4) ExoQuick precipitation methods (System Biosciences, Mountain View, CA, www.systembio.com, and Life Technologies, Foster City, CA, www.lifetechnologies. com), based on size-based precipitation approaches, a process that is relatively short, requiring less than 2hours, and proven to be efficient, reliable and reproducible when compared to the other methods.

Exosomes can be produced by the endocytic and exocytic activity in physiological and physiopathologic conditions [71,72]. A number of proteins families were identified in exosomes and many of these, such as heat shock proteins, annexins, and proteins of the Rab family, are primarily involved in intracellular assembly and trafficking of exosomes, and may not be required further after the vesicles are secreted [71]. Other ubiquitous proteins are involved in antigen presentation, as they can bind antigenic peptides and participate in loading peptides onto MHC molecules [73]. Tetraspanins are one of the most abundant protein families that is found in exosomes, consisting of a large number of transmembrane proteins. Several members of this family, such as CD9, CD63, CD81 and CD82 are highly enriched in exosomes. Tetraspanins interact with many protein partners including MHC molecules and integrins, suggesting that they are involved in the organization of large molecular complexes and membrane subdomains $[66,74]$. Integrins are another group of abundant proteins detected in exosomes, where they exist as heterodimers of $\alpha$ and $\beta$ subunits, and function as adhesion molecules facilitating binding to the extracellular matrix [75].

\section{Exosome lipids composition}

The lipid composition of mast cell-derived exosomes includes lysophosphatidylcholine, sphingomyelin, phosphatidylcholine, phosphatidylserine, phosphatidylethanolamine cholesterol and diglyceride [76]. It has been indicated that phosphatidylserine is a key determinant for the interaction of membrane vesicles with target cells although oxidized lipids which may also indicates that play a role. Phosphatidylserine and microparticles of different cellular origin can bind to platelet CD36 scavenger receptor, leading to increase ADP-dependent platelet activation and augmented thrombosis in mice [77]. The phosphatidylserine-moiety of endothelial microparticles can interact with endothelial phosphatidylserine receptor in an annexin I-dependent manner to prevent endothelial apoptosis [78]. It seems that when comparing these lipids with their parent cells, membranes of extracellular vesicles are enriched with phosphatidylserine, disaturated phosphatidylethanolamine, disaturated phosphatidylcholine, sphingomyelin, ganglioside GM3, and cholesterol $[79,80]$. These enriched lipids as well as lipid-raft-associated proteins in vesicular membranes provide extracellular vesicles with stability and structural rigidity $[81,82]$.

\section{Exosome miRNAs composition}

MicroRNAs (miRNAs) are non-coding RNA (19-22 nucleotides) that post-transcriptionally regulate gene expression by base-pairing with the 3 ' untranslated region of complementary messenger RNA targets. As mentioned above, miRNAs were found to be present in human plasma and serum in a remarkably stable and cell independent form, and their discovery has led to renewed interest in their use as novel non-invasive biomarkers in the context of physiological and pathophysiological conditions, including cancer and cardiovascular disease [83-87]. In addition to the classical mechanisms such as direct cell-cell contact or chemical receptor-mediated events, recent studies demonstrated that the transfer of exosome-derived unique miRNAs to recipient cells is an alternative mechanism enabling gene-based communication between cells [60]. Thus, RNA containing exosomes may represent alternate pathways of cellular communication with significant implications in the modification of cell phenotypes in response to homeostatic pertubations. As such, specific miRNAs such as let-7, miR-1, miR-15, miR-16, miR-151 and miR 375 which play role in angiogenesis, hematopoiesis, exocytosis and tumorigenesis have been reported in exosomes [74].

\section{Exosome functions}

To understand the biological function of exosomes, a number of transcriptomic and proteomic profiling analyses have been performed $[71,67,79]$. Exosomes can activate or inactivate different pathways on surrounding or remotely-located cells, depending on their molecular composition, which is 
influenced by the activation state of the secreting cell [88]. The assessment of biological functions of exosomes showed that they can deliver specifically their cargo from the donor to recipient cells. The molecular composition of exosomes reflects the specialized function (s) of their original cells. Through their ability to bind target cells, they are likely to modulate selected cellular activities, such as vascular homeostasis, and antigen presentation. The presence of exosomes in blood and tissues in vivo, suggests their participation in physiological and/or pathological processes, such as stimulation of regulatory T-cell lymphocytes, induction of protection against allergic sensitization, induction of cytokine production, and induction of tumor growth [39,66,89-92].

\section{Exosomes and endothelium}

Exosomes are released from endothelial cells [93] and cardiomyocytes [94,95]. Gupta and colleagues showed that the levels of exosome-mediated secretion of HSP60 from adult cardiomyocytes were increased three-fold in mild hypoxia [95], and Waldenstrom and colleagues explored the mRNA content of exosomes released from cardiomyocytes under normal conditions, and identified 1,520 mRNA by microarray analysis [94]. In addition, proteomics analysis of endothelial exosomes revealed about 1,354 distinctive proteins, while microarray analysis revealed 1,992 mRNA transcripts, and there were 21 of these transcripts in endothelial exosomes that were altered in their abundance due to hypoxia [93].

Studies of miRNAs are not only providing sources of disease biomarkers [20], but also enabling greater understanding of cardiovascular development under normal conditions and of remodeling processes in disease. In particular, miR-1, miR-133, miR-208, and miR-499 have been reported to be highly expressed in cardiac tissue from the early stages of heart development, regulating cell proliferation, differentiation, and apoptosis, as well as playing critical roles in several cardiac diseases [96]. Recent studies of circulating miRNA-133a levels showed levels were increased upon the onset of acute myocardial infarction, and also elevated with unstable angina pectoris and Takotsubo cardiomyopathy, even in the absence of elevation of serum creatine phosphokinase or cardiac troponin, two standard markers of acute cardiac insults [97].

Several reports using primary rodent cardiomyocytes (in vitro) have provided evidence of exosome secretion [95,98]. For example, Cheng and colleagues [99] detected significantly higher levels of miR-1 and miR-208 in urinary exosomes derived from acute myocardial infarction (MI) patients and in the circulating blood of rats after acute MI. Furthermore, the cardioprotective miR-214 that is secreted via exosomes from human endothelial cells has been shown to be up-regulated in the heart after acute ischemia and also altered in the plasma of coronary artery disease patients, indicating the severity of the disease. Recent work from several laboratories including ours has identified alterations in specific microvesicles in the plasma that not only exhibit severity-dependent changes but also provide suggestions as to the cellular sources of such microvesicles and their potential implications in cardiovascular disease in children [100-104].

\section{Exosome transfer miRNAs}

As mentioned above, exosomes have been found to contain different RNAs, including mRNAs, miRNAs, and long non-coding RNA (lncRNAs). In mammals, miRNAs can be transported by high-density lipoproteins (HDLs) and be delivered to recipient cells to modulate their function [105]. Inhibition of neuronal sphingomyelinase 2 (nSMase2), [32,106], increase the amount of miRNAs exported to HDLs by blocking the release of miRNA-loaded exosomes. Thus, nSMase 2 and the ceramide pathway might regulate different but coordinated pathways of miRNA secretion. Argonaute 2 (AGO2) is considered the key effector protein of miRNA-mediated silencing and can form circulating ribonucleoprotein complexes with miRNAs $[107,108]$.

The transfer of intact mRNAs from exosomes to target cells may alter the phenotypic features of recipient cells. Exosome-mediated RNA transfer is believed to be an effective method for cell signaling and the exosomal RNA will certainly impact biological processes in the recipient cells $[32,60,109]$. Exosomal RNAs have been implicated in many exosome-mediated biological functions [110]. In addition, exosomes are natural carriers of exogenous siRNA to human cells in vitro [111]. Therefore, the ability of exosomes to naturally carry and deliver RNA between cells could be a useful method to deliver therapeutic short interfering RNA (siRNA) to the desired target cells. Studies have shown that the packaging of RNAs into exosomes is selective because the RNA profiles in exosomes do not fully reflect the RNA profiles observed in the parental cells [29,31]. While exosomes have been shown to play functional roles in recipient cells, the RNA content of the exosomes may provide unique molecular signatures for disease diagnosis and prognosis [112]. It has been reported that exosomes from diseased individuals contained RNAs that were not found in healthy subjects $[50,112]$. Recently, the role of miRNAs in inflammation and metabolic and cardiovascular diseases has been highlighted [113-115].

\section{Exosome and the endothelial barrier}

Endothelial dysfunction (ED), an early risk marker of cardiovascular disease, refers to a loss of normal homeostatic function in the blood vessels, and is characterized by altered vasodilatory and vasoconstrictive functions and inflammatory activity [116]. ED is an early and sustained process involved in the development of vascular complications related 
to dyslipidemia, and cardiovascular disease such as hypertension, coronary artery disease and chronic heart failure $[117,118]$. In healthy subjects, the vascular endothelium, which forms the barrier between blood and the surrounding tissues, is known to efficiently respond to stress signals like hypoxia and inflammation by adaptation of cellular physiology and the secretion of cytokines and growth factors that recruit endothelial progenitor cells or cells that play a role in the innate immune response [119]. Also, it has been reported that endothelial cells secrete exosomes $[120,121]$ and several reports show that endothelial cells can also be targeted by exosomes derived from different cell types [122].

The tight junction complex is critically involved in the exchange of ions, solutes, and cells that travel across paracellular spaces. Tight junctions regulate the formation of apico-basal polarity and control proliferation, gene expression, or cell differentiation through signaling pathways that are activated by tight junction components [123]. Several proteins have been identified to be associated with tight junctions [124] such as occludin (OCLN) and claudins (CLD), and these are transmembrane spanning proteins forming the intercellular adhesions via hemophilic and heterophilic interactions. Zonula occludens-1 (ZO-1), $\mathrm{ZO}-2$, ZO-3, or cingulin, are located mintracellularly and anchortransmembrane proteins with the actin cytoskeleton
[123]. Tight junction components, such as occludin, claudins, or junctional adhesion molecules, are linked to the actin cytoskeleton by $\mathrm{ZO}$ proteins, thereby enabling these proteins to constitute major stabilizing factors of tight junctions. Accordingly, ZO proteins have been shown to be essential for tight junction formation [125]. Recent studies now show that exosomes from patients with cardiovascular disease or from endothelial cells exposed to stressful conditions can disrupt endothelial tight junctions and reflect the extent of endothelial dysfunction or of repair potential [126-134].

In the context of OSA, in depth exploration of the exosomal content is lacking. Initial work on microvesicles and OSA would definitely justify further efforts since a substantial degree of correlations between microvesicles from different cellular sources and cardiovascular outcomes including ED have been identified [135-145]. Similar observations are applicable in the context of obesity, whereby specific microvesicles appear to be closely associated with metabolic or cardiovascular outcomes [135-146]. Furthermore, children with obesity, OSA, or both may be at increased risk of CVD, but their identification is currently difficult. We postulate that exosomes isolated from children with CVD (+) will differ from those children that do not exhibit increased CVD risk (CVD (-)). Identification and validation of candidate exosomal miRNAs can then

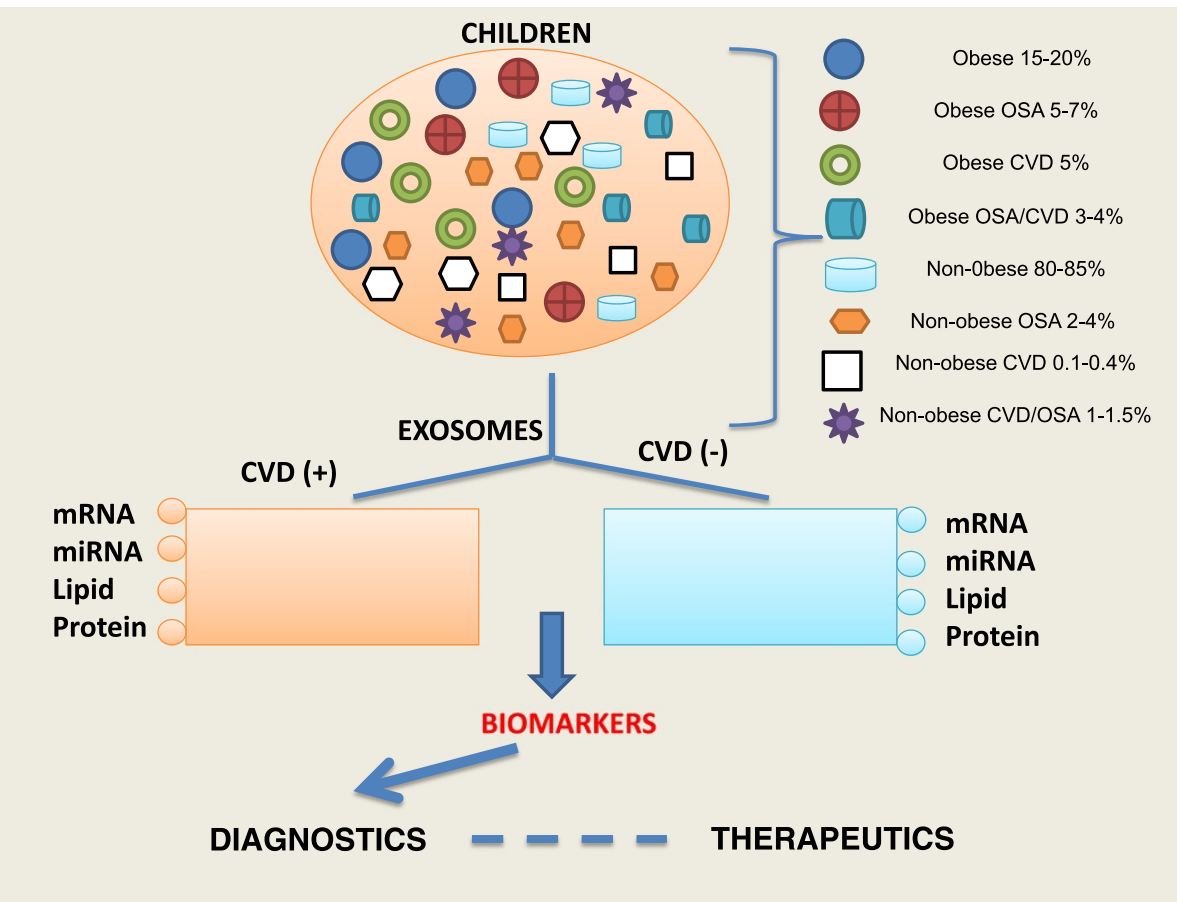

Figure 2 Schematic diagram illustrating the potential use of exosomal miRNAs to identify children at risk for cardiovascular disease (CVD (+)). Children with obesity, OSA, or both may be at increased risk of CVD but currently their identification is difficult. Exosomes isolated from children with CVD (+) will differ from those children that do not exhibit increased CVD risk (CVD (-)). Identification and validation of candidate exosomal miRNAs can then be used as biomarkers for diagnostic purposes and potentially provide insights into therapeutic strategies. 
be used as biomarkers for diagnostic purposes, and potentially provide insights into therapeutic strategies. We propose as illustrated in Figure 2, a schematic diagram illustrating the potential use of exosomal miRNAs to identify children at risk for cardiovascular disease.

\section{Exosomes in diagnosis and therapy}

As discussed above, circulating cell-free nucleic acids have promising potential as non-invasive diagnostic markers for pathological processes such as chronic inflammation, cancer and cardiovascular disease [147,148]. More recently, have emerged as possible vehicles for the delivery of therapeutic molecules, and have mainly been investigated in the context of cancer therapy on account of their T-cell stimulatory capacity. For instance, exosomes loaded with tumor antigens have been shown to stimulate CD4+ and CD8 $+\mathrm{T}$ cell lmphocytes, and exosomes from in vitro cultured antigen presenting cells (APCs) administrated in vivo can induce T-cell lymphocyte responses resulting in inhibition of tumor growth $[149,150]$. The first two promising phase I trials in human cancer have been published $[151,152]$ using exosomes from monocyte-derived DCs loaded with tumor antigens. The use of exosomes in cardiovascular diseases is being now intensively explored but unlikely to be readily applicable in children.

Despite the relative facility to collect exosomes from biological fluids, the actual use of exosome-derived proteins or miRNAs as biomarkers is, however, not yet implemented in clinical practice. Minimally invasive diagnostics (based on analysis of blood) or non-invasive diagnostics (using urine and saliva samples) are superior alternatives to traditional needle or excision biopsies due to the reduced patient pain and inconvenience, and greater speed and lower cost of analysis. Indeed, several companies have initiated development of the exosome-based diagnostics within the last three years. For example, a sensitive diagnostic of prostate cancer based on analysis of exosomal proteins was recently launched (www.CarisLifeSciences. com). Exosome diagnostics is developing biofluid-based molecular diagnostic tests for use in personalized medicine. The main focus thus far is on oncology or neurodiagnostics through exosome-based technology platforms (www.ExosomeDx.com; www.HansaBioMed.eu). We propose that similar to some of the proteomic biomarkers emerging in the context of pediatric sleep apnea and cardiovascular disease [153-157].

\section{Conclusion}

Cells communicate with each other via extracellular molecules, such as nucleotides, lipids, miRNA, or proteins. These molecules can then be released extracellularly by cells in microvesicles and bind to receptors on other cells, thus inducing intracellular signaling and modification of the intracellular physiological state of recipient cells. Exosomes have been isolated and characterized from many different biological fluids such as blood components, urine, amniotic fluids, malignant effusions, breast milk and bronchoalveolar lavage fluid and contain an array of proteins and lipids as well as genetic material such as mRNA and miRNA. The unique opportunities for the discovery and use of exosomes contents as clinical biomarkers of cardiovascular disease risk in obese children or in other groups of children with diseases associated with cardiovascular morbidities such as pediatric sleep apnea appears to be warranted. Indeed, the study of exosomes in the context of pediatric obesity or OSA will illustrate novel mechanisms of cell-cell and organ-organ communication, identify novel biomarkers of the disease and its complications, and potentially aid in the development of novel therapeutics.

\section{Competing interests}

The authors declare that they have no competing interests.

\section{Authors' contributions}

AK provided the conceptual design of the project, writing and editing final version of the manuscript. DG participated in writing and editing final version of the manuscript. Both authors read and approved the final manuscript.

\section{Funding sources}

DG is supported by National Institutes of Health grants HL-065270 and HL-086662.

Received: 25 May 2014 Accepted: 29 May 2014

Published: 10 June 2014

\section{References}

1. Abbasi F, Brown BW Jr, Lamendola C, McLaughlin T, Reaven GM: Relationship between obesity, insulin resistance, and coronary heart disease risk. J Am Coll Cardiol 2002, 40:937-943.

2. Kelishadi R: Childhood overweight, obesity, and the metabolic syndrome in developing countries. Epidemiol Rev 2007, 29:62-76.

3. Haslam DW, James WP: Obesity. Lancet 2005, 366:1197-1209.

4. Gozal D, Kheirandish-Gozal L: Cardiovascular morbidity in obstructive sleep apnea: oxidative stress, inflammation, and much more. Am J Respir Crit Care Med 2008, 177:369-375.

5. Bhattacharjee R, Alotaibi WH, Kheirandish-Gozal L, Capdevila OS, Gozal D: Endothelial dysfunction in obese non-hypertensive children without evidence of sleep disordered breathing. BMC Pediatr 2010, 10:8.

6. Aggoun Y, Farpour-Lambert NJ, Marchand LM, Golay E, Maggio AB, Beghetti M: Impaired endothelial and smooth muscle functions and arterial stiffness appear before puberty in obese children and are associated with elevated ambulatory blood pressure. Eur Heart J 2008, 29:792-799.

7. Reilly JJ, Kelly J: Long-term impact of overweight and obesity in childhood and adolescence on morbidity and premature mortality in adulthood: systematic review. Int J Obes (Lond) 2011, 35:891-898.

8. Kelly AS, Barlow SE, Rao G, Inge TH, Hayman LL, Steinberger J, Urbina EM, Ewing LJ, Daniels SR: Severe obesity in children and adolescents: identification, associated health risks, and treatment approaches: a scientific statement from the American Heart Association. Circulation 2013, 128:1689-1712.

9. Must A, Phillips SM, Naumova EN: Occurrence and timing of childhood overweight and mortality: findings from the Third Harvard Growth Study. J Pediatr 2012, 160:743-750.

10. Juhola J, Magnussen CG, Berenson GS, Venn A, Burns TL, Sabin MA, Srinivasan SR, Daniels SR, Davis PH, Chen W: Combined effects of child and adult elevated blood pressure on subclinical atherosclerosis: the International Childhood Cardiovascular Cohort Consortium. Circulation 2013, 128:217-224. 
11. Oikonen M, Laitinen $T$, Magnussen CG, Steinberger J, Sinaiko AR, Dwyer T, Venn A, Smith KJ, Hutri-Kahonen N, Pahkala K: Ideal cardiovascular health in young adult populations from the United States, Finland, and Australia and its association with cIMT: the International Childhood Cardiovascular Cohort Consortium. J Am Heart Assoc 2013, 2:e000244.

12. Sharma D, DasMahapatra P, Fernandez C, Chen W, Srinivasan SR, XU J, Berenson GS: The association of c-reactive protein with arterial compliance in asymptomatic young adults: the Bogalusa heart study. J Hum Hypertens 2013, 27:256-260.

13. Zhang Z, Kris-Etherton PM, Hartman TJ: Birth Weight and Risk Factors for Cardiovascular Disease and Type 2 Diabetes in US Children and Adolescents: 10 Year Results from NHANES. Matern Child Health J 2013, [Epub ahead of print].

14. Khoury M, Manlhiot C, McCrindle BW: Role of the waist/height ratio in the cardiometabolic risk assessment of children classified by body mass index. J Am Coll Cardiol 2013, 62:742-751.

15. Aronson JK: Biomarkers and surrogate endpoints. Br J Clin Pharmacol 2005, 59:491-494.

16. LaBaer J: So, you want to look for biomarkers (introduction to the special biomarkers issue). J Proteome Res 2005, 4:1053-1059.

17. Chugh S, Suen C, Gramolini A: Proteomics and mass spectrometry: what have we learned about the heart? Curr Cardiol Rev 2010, 6:124-133.

18. Mitchell PS, Parkin RK, Kroh EM, Fritz BR, Wyman SK, Pogosova-Agadjanyan EL, Peterson A, Noteboom J, O'Briant KC, Allen A: Circulating microRNAs as stable blood-based markers for cancer detection. Proc Natl Acad Sci U S A 2008, 105:10513-10518.

19. Gupta SK, Bang C, Thum T: Circulating microRNAs as biomarkers and potential paracrine mediators of cardiovascular disease. Circ CardiovasC Genet 2010, 3:484-488.

20. Haider BA, Baras AS, McCall MN, Hertel JA, Cornish TC, Halushka MK: A Critical Evaluation of microRNA Biomarkers in Non-Neoplastic Disease. PLoS One 2014, 9:e89565.

21. Huang Z, Huang D, Ni S, Peng Z, Sheng W, Du X: Plasma microRNAs are promising novel biomarkers for early detection of colorectal cancer. Int J Cancer 2010, 127:118-126.

22. Park NJ, Zhou H, Elashoff D, Henson BS, Kastratovic DA, Abemayor E, Wong DT: Salivary microRNA: discovery, characterization, and clinical utility for oral cancer detection. Clin Cancer Res 2009, 15:5473-5477.

23. Corsten MF, Dennert R, Jochems S, Kuznetsova T, Devaux Y, Hofstra L, Wagner DR, Staessen JA, Heymans S, Schroen B: Circulating MicroRNA-208b and MicroRNA-499 reflect myocardial damage in cardiovascular disease. Circ Cardiovasc Genet 2010, 3:499-506.

24. Resnick KE, Alder H, Hagan JP, Richardson DL, Croce CM, Cohn DE: The detection of differentially expressed microRNAs from the serum of ovarian cancer patients using a novel real-time PCR platform. Gynecol Oncol 2009, 112:55-59.

25. Omran A, Elimam D, Webster KA, Shehadeh LA, Yin F: MicroRNAs: a new piece in the paediatric cardiovascular disease puzzle. Cardiol Young 2013, 23:642-655.

26. Omran A, Elimam D, He F, Peng J, Yin F: Potential role of blood microRNAs as non-invasive biomarkers for early detection of asymptomatic coronary atherosclerosis in obese children with metabolic syndrome. Med Hypotheses 2012, 79:889-893.

27. Camussi G, Deregibus MC, Bruno S, Cantaluppi V, Biancone L: Exosomes/ microvesicles as a mechanism of cell-to-cell communication. Kidney Int 2010, 78:838-848.

28. Thery C, Ostrowski M, Segura E: Membrane vesicles as conveyors of immune responses. Nat Rev Immunol 2009, 9:581-593.

29. Valadi H, Ekstrom K, Bossios A, Sjostrand M, Lee JJ, Lotvall JO: Exosomemediated transfer of mRNAs and microRNAs is a novel mechanism of genetic exchange between cells. Nat Cell Biol 2007, 9:654-659.

30. Mathivanan S, Lim JW, Tauro BJ, Ji H, Moritz RL, Simpson RJ: Proteomics analysis of $A 33$ immunoaffinity-purified exosomes released from the human colon tumor cell line LIM1215 reveals a tissue-specific protein signature. Mol Cell Proteomics 2010, 9:197-208.

31. Skog J, Wurdinger T, van Rijn S, Meijer DH, Gainche L, Sena-Esteves M, Curn WT Jr, Carter BS, Krichevsky AM, Breakefield XO: Glioblastoma microvesicles transport RNA and proteins that promote tumour growth and provide diagnostic biomarkers. Nat Cell Biol 2008, 10:1470-1476.

32. Mittelbrunn M, Gutierrez-Vazquez C, Villarroya-Beltri C, Gonzalez S, Sanchez-Cabo F, Gonzalez MA, Bernad A, Sanchez-Madrid F: Unidirectional transfer of microRNA-loaded exosomes from T cells to antigenpresenting cells. Nat Commun 2011, 2:282.

33. Sherer NM, Mothes W: Cytonemes and tunneling nanotubules in cell-cell communication and viral pathogenesis. Trends Cell Biol 2008, 18:414-420

34. Mathivanan S, Fahner CJ, Reid GE, Simpson RJ: ExoCarta 2012: database of exosomal proteins, RNA and lipids. Nucleic Acids Res 2012, 40:D1241-D1244.

35. Jayachandran M, Miller VM, Heit JA, Owen WG: Methodology for isolation identification and characterization of microvesicles in peripheral blood. $\mathrm{J}$ Immunol Methods 2012, 375:207-214.

36. Hristov M, Erl W, Linder S, Weber PC: Apoptotic bodies from endothelial cells enhance the number and initiate the differentiation of human endothelial progenitor cells in vitro. Blood 2004, 104:2761-2766.

37. Pan BT, Teng K, Wu C, Adam M, Johnstone RM: Electron microscopic evidence for externalization of the transferrin receptor in vesicular form in sheep reticulocytes. J Cell Biol 1985, 101:942-948.

38. Harding C, Heuser J, Stahl P: Receptor-mediated endocytosis of transferrin and recycling of the transferrin receptor in rat reticulocytes. J Cell Biol 1983, 97:329-339.

39. Admyre C, Johansson SM, Qazi KR, Filen JJ, Lahesmaa R, Norman M, Neve EP, Scheynius A, Gabrielsson S: Exosomes with immune modulatory features are present in human breast milk. J Immuno/ 2007, 179:1969-1978.

40. Masyuk Al, Masyuk TV, Larusso NF: Exosomes in the pathogenesis, diagnostics and therapeutics of liver diseases. J Hepatol 2013, 59:621-625.

41. Vella $L$, Sharples RA, Nisbet RM, Cappai R, Hill AF: The role of exosomes in the processing of proteins associated with neurodegenerative diseases. Eur Biophys J 2008, 37:323-332.

42. Cosme J, Liu PP, Gramolini AO: The cardiovascular exosome: current perspectives and potential. Proteomics 2013, 13:1654-1659.

43. Thery C: Exosomes: secreted vesicles and intercellular communications. F1000 Biol Rep 2011, 3:15.

44. Raposo G, Nijman HW, Stoorvogel W, Liejendekker R, Harding CV, Melief CJ, Geuze HJ: B lymphocytes secrete antigen-presenting vesicles. J Exp Med 1996, 183:1161-1172.

45. Peters PJ, Geuze HJ, Van der Donk HA, Slot JW, Griffith JM, Stam NJ, Clevers $\mathrm{HC}$, Borst J: Molecules relevant for T cell-target cell interaction are present in cytolytic granules of human T lymphocytes. Eur J Immunol 1989, 19:1469-1475.

46. Zitvogel L, Regnault A, Lozier A, Wolfers J, Flament C, Tenza D, Ricciardi-Castagnoli P, Raposo G, Amigorena S: Eradication of established murine tumors using a novel cell-free vaccine: dendritic cell-derived exosomes. Nat Med 1998, 4:594-600.

47. Raposo G, Tenza D, Mecheri S, Peronet R, Bonnerot C, Desaymard C: Accumulation of major histocompatibility complex class II molecules in mast cell secretory granules and their release upon degranulation. Mol Biol Cell 1997, 8:2631-2645

48. Heijnen HF, Schiel AE, Fijnheer R, Geuze HJ, Sixma JJ: Activated platelets release two types of membrane vesicles: microvesicles by surface shedding and exosomes derived from exocytosis of multivesicular bodies and alpha-granules. Blood 1999, 94:3791-3799.

49. Wolfers J, Lozier A, Raposo G, Regnault A, Thery C, Masurier C, Flament C, Pouzieux S, Faure F, Tursz T: Tumor-derived exosomes are a source of shared tumor rejection antigens for CTL cross-priming. Nat Med 2001, 7:297-303.

50. Keller S, Rupp C, Stoeck A, Runz S, Fogel M, Lugert S, Hager HD, Abdel-Bakky MS, Gutwein P, Altevogt P: CD24 is a marker of exosomes secreted into urine and amniotic fluid. Kidney Int 2007, 72:1095-1102.

51. Taylor DD, Gercel-Taylor C: MicroRNA signatures of tumor-derived exosomes as diagnostic biomarkers of ovarian cancer. Gynecol Oncol 2008, 110:13-21.

52. Caby MP, Lankar D, Vincendeau-Scherrer C, Raposo G, Bonnerot C Exosomal-like vesicles are present in human blood plasma. Int Immunol 2005, 17:879-887.

53. Lasser C, Alikhani VS, Ekstrom K, Eldh M, Paredes PT, Bossios A, Sjostrand M, Gabrielsson S, Lotvall J, Valadi H: Human saliva, plasma and breast milk exosomes contain RNA: uptake by macrophages. J Trans/ Med 2011, 9:9.

54. Saman S, Kim W, Raya M, Visnick Y, Miro S, Saman S, Jackson B, McKee AC, Alvarez VE, Lee NC, Hall GF: Exosome-associated tau is secreted in tauopathy models and is selectively phosphorylated in cerebrospinal fluid in early Alzheimer disease. J Biol Chem 2012, 287:3842-3849.

55. Qiu S, Duan X, Geng X, Xie J, Gao H: Antigen-specific activities of CD8+ T cells in the nasal mucosa of patients with nasal allergy. Asian Pac J Allergy Immunol 2012, 30:107-113. 
56. Dimov I, Jankovic Velickovic L, Stefanovic V: Urinary exosomes. Scientific World Journal 2009, 9:1107-1118.

57. Bard MP, Hegmans JP, Hemmes A, Luider TM, Willemsen R, Severijnen LA, van Meerbeeck JP, Burgers SA, Hoogsteden HC, Lambrecht BN: Proteomic analysis of exosomes isolated from human malignant pleural effusions. Am J Respir Cell Mol Biol 2004, 31:114-121.

58. Mathivanan S, Ji H, Simpson RJ: Exosomes: extracellular organelles important in intercellular communication. J Proteomics 2010, 73:1907-1920.

59. van Niel G, Porto-Carreiro I, Simoes S, Raposo G: Exosomes: a common pathway for a specialized function. J Biochem 2006, 140:13-21.

60. Kosaka N, Iguchi H, Yoshioka Y, Takeshita F, Matsuki Y, Ochiya T: Secretory mechanisms and intercellular transfer of microRNAs in living cells. J Biol Chem 2010, 285:17442-17452.

61. Lakkaraju A, Rodriguez-Boulan E: Itinerant exosomes: emerging roles in cell and tissue polarity. Trends Cell Biol 2008, 18:199-209.

62. Savina A, Vidal M, Colombo Ml: The exosome pathway in K562 cells is regulated by Rab11. J Cell Sci 2002, 115:2505-2515.

63. Llorente A, van Deurs B, Sandvig K: Cholesterol regulates prostasome release from secretory lysosomes in PC-3 human prostate cancer cells. Eur J Cell Biol 2007, 86:405-415.

64. Mathivanan S, Simpson RJ: ExoCarta: A compendium of exosomal proteins and RNA. Proteomics 2009, 9:4997-5000.

65. Fevrier B, Raposo G: Exosomes: endosomal-derived vesicles shipping extracellular messages. Curr Opin Cell Biol 2004, 16:415-421.

66. Thery C, Zitvogel L, Amigorena S: Exosomes: composition, biogenesis and function. Nat Rev Immunol 2002, 2:569-579.

67. Thery C, Boussac M, Veron P, Ricciardi-Castagnoli P, Raposo G, Garin J, Amigorena S: Proteomic analysis of dendritic cell-derived exosomes: a secreted subcellular compartment distinct from apoptotic vesicles. J Immunol 2001, 166:7309-7318.

68. Johnstone RM, Adam M, Hammond JR, Orr L, Turbide C: Vesicle formation during reticulocyte maturation. Association of plasma membrane activities with released vesicles (exosomes). J Biol Chem 1987, 262:9412-9420.

69. Lamparski HG, Metha-Damani A, Yao JY, Patel S, Hsu DH, Ruegg C, Le Pecq JB: Production and characterization of clinical grade exosomes derived from dendritic cells. J Immunol Methods 2002, 270:211-226.

70. Clayton A, Court J, Navabi H, Adams M, Mason MD, Hobot JA, Newman GR, Jasani B: Analysis of antigen presenting cell derived exosomes, based on immuno-magnetic isolation and flow cytometry. J Immunol Methods 2001, 247:163-174.

71. Simpson RJ, Jensen SS, Lim JW: Proteomic profiling of exosomes: current perspectives. Proteomics 2008, 8:4083-4099.

72. Pisitkun T, Shen RF, Knepper MA: Identification and proteomic profiling of exosomes in human urine. Proc Natl Acad Sci U S A 2004, 101:13368-13373.

73. Srivastava P: Interaction of heat shock proteins with peptides and antigen presenting cells: chaperoning of the innate and adaptive immune responses. Annu Rev Immunol 2002, 20:395-425.

74. Taylor DD, Zacharias W, Gercel-Taylor C: Exosome isolation for proteomic analyses and RNA profiling. Methods Mol Biol 2011, 728:235-246.

75. Barczyk M, Carracedo S, Gullberg D: Integrins. Cell Tissue Res 2010, 339:269-280.

76. Laulagnier K, Motta C, Hamdi S, Roy S, Fauvelle F, Pageaux JF, Kobayashi T, Salles JP, Perret B, Bonnerot C, Record M: Mast cell- and dendritic cellderived exosomes display a specific lipid composition and an unusual membrane organization. Biochem J 2004, 380:161-171.

77. Ghosh A, Li W, Febbraio M, Espinola RG, McCrae KR, Cockrell E, Silverstein RL: Platelet CD36 mediates interactions with endothelial cell-derived microparticles and contributes to thrombosis in mice. J Clin Invest 2008, 118:1934-1943

78. Jansen F, Yang X, Hoyer FF, Paul K, Heiermann N, Becher MU, Abu Hussein N, Kebschull M, Bedorf J, Franklin BS: Endothelial microparticle uptake in target cells is annexin I/phosphatidylserine receptor dependent and prevents apoptosis. Arterioscler Thromb Vasc Biol 2012, 32:1925-1935.

79. Vidal M, Sainte-Marie J, Philippot JR, Bienvenue A: Asymmetric distribution of phospholipids in the membrane of vesicles released during in vitro maturation of guinea pig reticulocytes: evidence precluding a role for "aminophospholipid translocase". J Cell Physiol 1989, 140:455-462.

80. Wubbolts R, Leckie RS, Veenhuizen PT, Schwarzmann G, Mobius W, Hoernschemeyer J, Slot JW, Geuze HJ, Stoorvogel W: Proteomic and biochemical analyses of human B cell-derived exosomes. Potential implications for their function and multivesicular body formation. J Biol Chem 2003, 278:10963-10972.
81. Needham D, Nunn RS: Elastic deformation and failure of lipid bilayer membranes containing cholesterol. Biophys J 1990, 58:997-1009.

82. Abi-Rizk G, Besson F: Interactions of Triton X-100 with sphingomyelin and phosphatidylcholine monolayers: influence of the cholesterol content. Colloids Surf B Biointerfaces 2008, 66:163-167.

83. Scholer N, Langer C, Dohner H, Buske C, Kuchenbauer F: Serum microRNAs as a novel class of biomarkers: a comprehensive review of the literature. Exp Hematol 2010, 38:1126-1130.

84. Scholer N, Langer C, Kuchenbauer F: Circulating microRNAs as biomarkers True Blood? Genome Med 2011, 3:72.

85. Spinale FG, Zile MR: Integrating the myocardial matrix into heart failure recognition and management. Circ Res 2013, 113:725-738.

86. DiStefano JK, Taila M, Alvarez ML: Emerging roles for miRNAs in the development, diagnosis, and treatment of diabetic nephropathy. Curr Diab Rep 2013, 13:582-591.

87. Van Aelst LN, Heymans S: MicroRNAs as biomarkers for ischemic heart disease. J Cardiovasc Transl Res 2013, 6:458-470.

88. Fomina AF, Deerinck TJ, Ellisman MH, Cahalan MD: Regulation of membrane trafficking and subcellular organization of endocytic compartments revealed with FM1-43 in resting and activated human T cells. Exp Cell Res 2003, 291:150-166.

89. Ogawa Y, Kanai-Azuma M, Akimoto Y, Kawakami H, Yanoshita R: Exosome-like vesicles in Gloydius blomhoffii blomhoffii venom. Toxicon 2008, 51:984-993.

90. Prado N, Marazuela EG, Segura E, Fernandez-Garcia H, Villalba M, Thery C, Rodriguez R, Batanero E: Exosomes from bronchoalveolar fluid of tolerized mice prevent allergic reaction. J Immunol 2008, 181:1519-1525.

91. Keller S, Konig AK, Marme F, Runz S, Wolterink S, Koensgen D, Mustea A, Sehouli J, Altevogt P: Systemic presence and tumor-growth promoting effect of ovarian carcinoma released exosomes. Cancer Lett 2009, 278:73-81.

92. Cho JA, Yeo DJ, Son HY, Kim HW, Jung DS, Ko JK, Koh JS, Kim YN, Kim CW: Exosomes: a new delivery system for tumor antigens in cancer immunotherapy. Int J Cancer 2005, 114:613-622.

93. de Jong OG, Verhaar MC, Chen Y, Vader P, Gremmels H, Posthuma G, Schiffelers RM, Gucek M, van Balkom BW: Cellular stress conditions are reflected in the protein and RNA content of endothelial cell-derived exosomes. J Extracell Vesicles 2012, 1:18396.

94. Waldenstrom A, Genneback N, Hellman U, Ronquist G: Cardiomyocyte microvesicles contain DNA/RNA and convey biological messages to target cells. PLoS One 2012, 7:e34653.

95. Gupta S, Knowlton AA: HSP60 trafficking in adult cardiac myocytes: role of the exosomal pathway. Am J Physiol Heart Circ Physiol 2007, 292:H3052-H3056.

96. Espinoza-Lewis RA, Wang DZ: MicroRNAs in heart development. Curr Top Dev Biol 2012, 100:279-317

97. Kuwabara Y, Ono K, Horie T, Nishi H, Nagao K, Kinoshita M, Watanabe S, Baba O, Kojima Y, Shizuta S, Imai M, Tamura T, Kita T, Kimura T: Increased microRNA-1 and microRNA-133a levels in serum of patients with cardiovascular disease indicate myocardial damage. Circ Cardiovasc Genet 2011, 4:446-454.

98. Yu X, Deng L, Wang D, Li N, Chen X, Cheng X, Yuan J, Gao X, Liao M, Wang M, Liao Y: Mechanism of TNF-alpha autocrine effects in hypoxic cardiomyocytes: initiated by hypoxia inducible factor 1alpha, presented by exosomes. J Mol Cell Cardiol 2012, 53:848-857

99. Cheng Y, Wang X, Yang J, Duan X, Yao Y, Shi X, Chen Z, Fan Z, Liu X, Qin S, Tang $X$, Zhang C: A translational study of urine miRNAs in acute myocardial infarction. J Mol Cell Cardiol 2012, 53:668-676.

100. Tantawy AA, Adly AA, Ismail EA, Habeeb NM, Farouk A: Circulating platelet and erythrocyte microparticles in young children and adolescents with sickle cell disease: Relation to cardiovascular complications. Platelets 2013, 24:605-614.

101. Kheirandish-Gozal L: The Endothelium as a Target in Pediatric OSA. Front Neurol 2012, 3:92.

102. Gunduz Z, Dursun I, Tulpar S, Bastug F, Baykan A, Yikilmaz A, Patiroglu T, Poyrazoglu HM, Akin L, Yel S, Dusunsel R: Increased endothelial microparticles in obese and overweight children. J Pediatr Endocrinol Metab 2012, 25:1111-1117.

103. Kim J, Bhattacharjee R, Kheirandish-Gozal L, Spruyt K, Gozal D: Circulating microparticles in children with sleep disordered breathing. Chest 2011, 140:408-417.

104. Dursun I, Poyrazoglu HM, Gunduz Z, Ulger H, Yykylmaz A, Dusunsel R, Patyroglu T, Gurgoze M: The relationship between circulating endothelia microparticles and arterial stiffness and atherosclerosis in children with chronic kidney disease. Nephrol Dial Transplant 2009, 24:2511-2518. 
105. Vickers KC, Palmisano BT, Shoucri BM, Shamburek RD, Remaley AT: MicroRNAs are transported in plasma and delivered to recipient cells by high-density lipoproteins. Nat Cell Biol 2011, 13:423-433.

106. Trajkovic K, Hsu C, Chiantia S, Rajendran L, Wenzel D, Wieland F, Schwille P, Brugger B, Simons M: Ceramide triggers budding of exosome vesicles into multivesicular endosomes. Science 2008, 319:1244-1247.

107. Arroyo JD, Chevillet JR, Kroh EM, Ruf IK, Pritchard CC, Gibson DF, Mitchell PS, Bennett CF, Pogosova-Agadjanyan EL, Stirewalt DL: Argonaute2 complexes carry a population of circulating microRNAs independent of vesicles in human plasma. Proc Natl Acad Sci U S A 2011, 108:5003-5008.

108. Turchinovich A, Weiz L, Langheinz A, Burwinkel B: Characterization of extracellular circulating microRNA. Nucleic Acids Res 2011, 39:7223-7233.

109. Montecalvo A, Larregina AT, Shufesky WJ, Stolz DB, Sullivan ML, Karlsson JM, Baty CJ, Gibson GA, Erdos G, Wang Z: Mechanism of transfer of functional microRNAs between mouse dendritic cells via exosomes. Blood 2012, 119:756-766.

110. Peinado H, Aleckovic M, Lavotshkin S, Matei I, Costa-Silva B, Moreno-Bueno G, Hergueta-Redondo M, Williams C, Garcia-Santos G, Ghajar C: Melanoma exosomes educate bone marrow progenitor cells toward a pro-metastatic phenotype through MET. Nat Med 2012, 18:883-891.

111. Shtam TA, Kovalev RA, Varfolomeeva EY, Makarov EM, Kil YV, Filatov MV: Exosomes are natural carriers of exogenous siRNA to human cells in vitro. Cell Commun Signal 2013, 11:88.

112. Rabinowits G, Gercel-Taylor C, Day JM, Taylor DD, Kloecker GH: Exosomal microRNA: a diagnostic marker for lung cancer. Clin Lung Cancer 2009, 10:42-46.

113. Fernandez-Hernando C, Ramirez CM, Goedeke L, Suarez Y: MicroRNAs in metabolic disease. Arterioscler Thromb Vasc Biol 2013, 33:178-185.

114. Schroen B, Heymans S: Small but smart-microRNAs in the centre of inflammatory processes during cardiovascular diseases, the metabolic syndrome, and ageing. Cardiovasc Res 2012, 93:605-613.

115. Thum T, Mayr M: Review focus on the role of microRNA in cardiovascular biology and disease. Cardiovasc Res 2012, 93:543-544.

116. Davignon J, Ganz P: Role of endothelial dysfunction in atherosclerosis. Circulation 2004, 109:|||27-|||32.

117. Hirata Y, Nagata D, Suzuki E, Nishimatsu H, Suzuki J, Nagai R: Diagnosis and treatment of endothelial dysfunction in cardiovascular disease. Int Heart J 2010, 51:1-6.

118. Versari D, Daghini E, Virdis A, Ghiadoni L, Taddei S: Endothelial dysfunction as a target for prevention of cardiovascular disease. Diabetes Care 2009, 32(Suppl 2):S314-S321

119. Goligorsky MS, Kuo MC, Patschan D, Verhaar MC: Review article: endothelial progenitor cells in renal disease. Nephrology (Carlton) 2009, 14:291-297.

120. Zhan R, Leng X, Liu X, Wang X, Gong J, Yan L, Wang L, Wang Y, Wang X, Qian $L$ : Heat shock protein 70 is secreted from endothelial cells by a non-classical pathway involving exosomes. Biochem Biophys Res Commun 2009, 387:229-233.

121. Sheldon H, Heikamp E, Turley H, Dragovic R, Thomas $P$, Oon CE, Leek R, Edelmann M, Kessler B, Sainson RC: New mechanism for Notch signaling to endothelium at a distance by Delta-like 4 incorporation into exosomes. Blood 2010, 116:2385-2394.

122. Al-Nedawi K, Szemraj J, Cierniewski CS: Mast cell-derived exosomes activate endothelial cells to secrete plasminogen activator inhibitor type 1. Arterioscler Thromb Vasc Biol 2005, 25:1744-1749.

123. Guillemot L, Paschoud S, Pulimeno P, Foglia A, Citi S: The cytoplasmic plaque of tight junctions: a scaffolding and signalling center. Biochim Biophys Acta 2008, 1778:601-613.

124. Gonzalez-Mariscal L, Betanzos A, Nava P, Jaramillo BE: Tight junction proteins. Prog Biophys Mol Biol 2003, 81:1-44.

125. Umeda K, Ikenouchi J, Katahira-Tayama S, Furuse K, Sasaki H, Nakayama M, Matsui T, Tsukita S, Furuse M, Tsukita S: ZO-1 and ZO-2 independently determine where claudins are polymerized in tight-junction strand formation. Cell 2006, 126:741-754.

126. Chironi GN, Boulanger CM, Simon A, Dignat-George F, Freyssinet JM, Tedgui A: Endothelial microparticles in diseases. Cell Tissue Res 2009, 335:143-151.

127. Salomon C, Ryan J, Sobrevia L, Kobayashi M, Ashman K, Mitchell M, Rice GE: Exosomal signaling during hypoxia mediates microvascular endothelial cell migration and vasculogenesis. PLoS One 2013, 8:e68451.

128. van Balkom BW, de Jong OG, Smits M, Brummelman J, den Ouden K, de Bree PM, van Eijndhoven MA, Pegtel DM, Stoorvogel W, Wurdinger T,
Verhaar MC: Endothelial cells require miR-214 to secrete exosomes that suppress senescence and induce angiogenesis in human and mouse endothelial cells. Blood 2013, 121:3997-4006. S3991-3915.

129. Pallet N, Sirois I, Bell C, Hanafi LA, Hamelin K, Dieude M, Rondeau C, Thibault $P$, Desjardins M, Hebert MJ: A comprehensive characterization of membrane vesicles released by autophagic human endothelial cells. Proteomics 2013, 13:1108-1120.

130. Mocharla P, Briand S, Giannotti G, Dorries C, Jakob P, Paneni F, Luscher T, Landmesser $\mathrm{U}$ : AngiomiR-126 expression and secretion from circulating CD34(+) and CD14(+) PBMCs: role for proangiogenic effects and alterations in type 2 diabetics. Blood 2013, 121:226-236.

131. Yuana Y, Sturk A, Nieuwland R: Extracellular vesicles in physiological and pathological conditions. Blood Rev 2013, 27:31-39.

132. Hergenreider E, Heydt S, Treguer K, Boettger T, Horrevoets AJ, Zeiher AM, Scheffer MP, Frangakis AS, Yin X, Mayr M: Atheroprotective communication between endothelial cells and smooth muscle cells through miRNAs. Nat Cell Biol 2012, 14:249-256.

133. Dignat-George F, Boulanger CM: The many faces of endothelial microparticles. Arterioscler Thromb Vasc Biol 2011, 31:27-33.

134. Aharon A, Tamari T, Brenner B: Monocyte-derived microparticles and exosomes induce procoagulant and apoptotic effects on endothelial cells. Thromb Haemost 2008, 100:878-885.

135. Stiefel P, Sanchez-Armengol MA, Villar J, Vallejo-Vaz A, Moreno-Luna R, Capote F: Obstructive sleep apnea syndrome, vascular pathology, endothelial function and endothelial cells and circulating microparticles. Arch Med Res 2013, 44:409-414.

136. Tual-Chalot S, Fatoumata K, Priou P, Trzepizur W, Gaceb A, Contreras C, Prieto D, Martinez MC, Gagnadoux F, Andriantsitohaina R: Circulating microparticles from patients with obstructive sleep apnea enhance vascular contraction: mandatory role of the endothelium. Am J Pathol 2012, 181:1473-1482.

137. Feng J, Zhang D, Chen B: Endothelial mechanisms of endothelial dysfunction in patients with obstructive sleep apnea. Sleep Breath 2012, 16:283-294.

138. Priou P, Gagnadoux F, Tesse A, Mastronardi ML, Agouni A, Meslier N, Racineux JL, Martinez MC, Trzepizur W, Andriantsitohaina R: Endothelial dysfunction and circulating microparticles from patients with obstructive sleep apnea. Am J Pathol 2010, 177:974-983.

139. Yun CH, Jung KH, Chu K, Kim SH, Ji KH, Park HK, Kim HC, Lee ST, Lee SK, Roh JK: Increased circulating endothelial microparticles and carotid atherosclerosis in obstructive sleep apnea. J Clin Neurol 2010, 6:89-98.

140. Ayers L, Ferry B, Craig S, Nicoll D, Stradling JR, Kohler M: Circulating cellderived microparticles in patients with minimally symptomatic obstructive sleep apnoea. Eur Respir J 2009, 33:574-580.

141. Kranendonk ME, de Kleijn DP, Kalkhoven E, Kanhai DA, Uiterwaal CS, van der Graaf Y, Pasterkamp G, Visseren FL, Group SS: Extracellular vesicle markers in relation to obesity and metabolic complications in patients with manifest cardiovascular disease. Cardiovasc Diabetol 2014, 13:37.

142. Hulsmans M, Holvoet P: MicroRNA-containing microvesicles regulating inflammation in association with atherosclerotic disease. Cardiovasc Res 2013, 100:7-18.

143. Stepanian A, Bourguignat L, Hennou S, Coupaye M, Hajage D, Salomon L, Alessi MC, Msika S, de Prost D: Microparticle increase in severe obesity: Not related to metabolic syndrome and unchanged after massive weight loss. Obesity (Silver Spring) 2013, 11:2236-2243.

144. Muller G: Microvesicles/exosomes as potential novel biomarkers of metabolic diseases. Diabetes Metab Syndr Obes 2012, 5:247-282.

145. Morel O, Luca F, Grunebaum L, Jesel L, Meyer N, Desprez D, Robert S, Dignat-George F, Toti F, Simon C, Goichot B: Short-term very low-calorie diet in obese females improves the haemostatic balance through the reduction of leptin levels, PAI- 1 concentrations and a diminished release of platelet and leukocyte-derived microparticles. Int J Obes (Lond) 2011, 35:1479-1486.

146. Esposito K, Ciotola M, Schisano B, Gualdiero R, Sardelli L, Misso L, Giannetti G, Giugliano D: Endothelial microparticles correlate with endothelial dysfunction in obese women. J Clin Endocrinol Metab 2006, 91:3676-3679.

147. Cortez MA, Bueso-Ramos C, Ferdin J, Lopez-Berestein G, Sood AK, Calin GA: MicroRNAs in body fluids-the mix of hormones and biomarkers. Nat Rev Clin Oncol 2011, 8:467-477.

148. Small EM, Olson EN: Pervasive roles of microRNAs in cardiovascular biology. Nature 2011, 469:336-342. 
149. Amigorena S: Anti-tumour immunotherapy using dendritic-cell-derived exosomes. Res Immunol 1998, 149:661-662.

150. Hsu DH, Paz P, Villaflor G, Rivas A, Mehta-Damani A, Angevin E, Zitvogel L, Le Pecq JB: Exosomes as a tumor vaccine: enhancing potency through direct loading of antigenic peptides. J Immunother 2003, 26:440-450.

151. Escudier B, Dorval T, Chaput N, Andre F, Caby MP, Novault S, Flament C, Leboulaire C, Borg C, Amigorena S: Vaccination of metastatic melanoma patients with autologous dendritic cell (DC) derived-exosomes: results of thefirst phase I clinical trial. J Trans/ Med 2005, 3:10.

152. Morse MA, Garst J, Osada T, Khan S, Hobeika A, Clay TM, Valente N, Shreeniwas R, Sutton MA, Delcayre A: A phase I study of exosome immunotherapy in patients with advanced non-small cell lung cancer. J Transl Med 2005, 3:9.

153. Patacchioli FR, Tabarrini A, Ghiciuc CM, Dima-Cozma LC, Prete A, Bianchini C, Nicoletti F, Gozal D, Villa MP: Salivary biomarkers of obstructive sleep apnea syndrome in children. Pediatr Pulmonol 2014, [Epub ahead of print].

154. Gozal D: Serum, urine, and breath-related biomarkers in the diagnosis of obstructive sleep apnea in children: is it for real? Curr Opin Pulm Med 2012, 18:561-567.

155. Gozal D, Jortani S, Snow AB, Kheirandish-Gozal L, Bhattacharjee R, Kim J, Capdevila OS: Two-dimensional differential in-gel electrophoresis proteomic approaches reveal urine candidate biomarkers in pediatric obstructive sleep apnea. Am J Respir Crit Care Med 2009, 180:1253-1261.

156. Piran S, Liu P, Morales A, Hershberger RE: Where genome meets phenome: rationale for integrating genetic and protein biomarkers in the diagnosis and management of dilated cardiomyopathy and heart failure. J Am Coll Cardiol 2012, 60:283-289.

157. Yu HR, Kuo HC, Sheen JM, Wang L, Lin IC, Wang CL, Yang KD: A unique plasma proteomic profiling with imbalanced fibrinogen cascade in patients with Kawasaki disease. Pediatr Allergy Immunol 2009, 20:699-707.

doi:10.1186/1479-5876-12-162

Cite this article as: Khalyfa and Gozal: Exosomal miRNAs as potential biomarkers of cardiovascular risk in children. Journal of Translational Medicine 2014 12:162

\section{Submit your next manuscript to BioMed Central and take full advantage of:}

- Convenient online submission

- Thorough peer review

- No space constraints or color figure charges

- Immediate publication on acceptance

- Inclusion in PubMed, CAS, Scopus and Google Scholar

- Research which is freely available for redistribution 